\title{
Choosing Regression Models for Biomass Prediction Equations
}

\author{
by
}

Bijan Payandeh1

\begin{abstract}
This paper briefly describes the underlying assumptions and inherent drawbacks of logarithmic regression models commonly used to develop biomass prediction equations. Superiority of simple nonlinear models over both the logarithmic and multiple linear regression models is discussed and demonstrated on two data sets.
\end{abstract}

\section{Résumé}

Ce document décrit brièvement les suppositions sous-jacentes et les inconvénients rattachés aux modèles de régression logarithmique employés pour développer des équations de prédiction touchant la biomasse. L'auteur étudie et démontre, au moyen de deux séries de données, la supériorité des modèles simples non linéaires tant sur les modèles de régression logarithmiques que linéaires multiples.

\section{Introduction}

Foresters, wildlife scientists, range managers and other biologists have long been concerned with developing methods for predicting land productivity in terms of usable wood and fibre, i.e., biomass. In the case of wood, it is well known that tree or stand biomass (either fresh or oven-dry weight) may be expressed as a simple exponential or power function (allometric function) of individual tree or average stand diameter.

Logarithmic transformation has been the traditional means of linearizing such nonlinear relationships, mainly because nonlinear relationships are difficult to solve without the aid of high speed computers. Such a transformation has several inherent drawbacks, including the assumption of a multiplicative error term in the model and difficulties in evaluating the usual measures of goodness of fit such as $\mathrm{R}^{2}$ and standard error of the estimate (SEE) in terms of the original data. In addition logarithmic models usually result in biased estimates and are less precise than nonlinear models in terms of the untransformed data.

Although most of the above shortcomings of logarithmic transformation have been pointed out in statistical texts and articles (cf. Draper and Smith 1966, Furnival 1961, Newnham 1967, Kozak 1970, Baskerville 1972, Munro 1974 and others), many researchers continue to use logarithmic models in biomass and other similar studies. Tree or stand biomass is usually expressed as a function of diameter or diameter and height. Biomass equations containing diameter as a single independent variable are analogous to local volume equations while those containing both diameter and height are analogous to standard volume equations (Husch et al. 1972).

Most of the biomass equations developed to date (Stanek and State 1978) have been based on small localized data sets. To provide regional or standard biomass equations and to avoid logarithmic transformation, Evert and Alemdag (1979) proposed that equations based on multiple linear regression models be developed employing tree diameter,

${ }^{1}$ Great Lakes Forest Research Centre, Canadian Forestry Service, Sault Ste. Marie, Ont. P6A 5M7. height, their squares and cross products and other variables such as stand age, density, etc., as independent variables. However, a review of biomass studies in general and the results of two recent studies (Crow 1978), Green and Grigal 1978 ) in particular indicate that biomass is rather insensitive to tree height across broad regions-it is primarily a function of diameter. This happy situation should extend the geographical region across which one may use biomass equations.

The objective of this paper is to describe briefly three of the main regression models employed in developing biomass equations, to point out the inherent drawbacks of logarithmic models, and finally to compare the suitability of simple power functions with other models for developing biomass equations based on two sets of data.

\section{The Two Basic Regression Models}

Draper and Smith (1966) and others have adequately described the two basic types of linear types of linear (in the parameters to be estimated) and nonlinear regression models and their underlying assumptions.

Linear, $\quad Y=\beta X+\varepsilon$

Nonlinear, $Y=X^{\beta}+\varepsilon$

where: $\quad Y=(n \times 1)$ vector of observations,

$X=(n \times p)$ matrix of known form,

$\beta=(p \times 1)$ vector of parameters,

$\varepsilon=(n \times 1)$ vector of errors.

The nonlinear (in parameters to be estimated) model (2) can be subdivided into two types: "intrinsically linear" and "intrinsically nonlinear". If a model is intrinsically linear it can be expressed by a suitable transformation of the variables into standard linear model form (1). If a nonlinear model cannot be expressed in this form, then it is intrinsically nonlinear. An example of the intrinsically linear model is the multiplicative model which requires transformation of both dependent and independent variables such as models (3) and (4) below:

$$
Y=\beta_{0} X_{1}^{\beta_{1}} X_{2}^{\beta_{2}} X_{3}{ }_{3 \varepsilon}
$$

where: $\beta_{0}, \beta_{1}, \beta_{2}, \beta_{3}$ are model parameters and $\varepsilon$ is a multiplicative random error. If natural logarithms of the above model are used it can be converted into the linear model form:

1n $Y=1 n \beta_{0}+\beta_{1} \ln X_{1}+\beta_{2} 1 n X_{2}+\beta_{3} 1 n X_{3}+1 n \varepsilon$

Since model (4) is in the form of model (1), i.e., linear in parameters to be estimated, it can be handled by the standard linear regression and least squares estimation procedure. It must be recognized, however, that the requirements for valid tests of significance and confidence intervals are now $1 \mathrm{n} \varepsilon \mathrm{N}\left(0, \sigma^{2}\right)$ rather than $\varepsilon$. Therefore, researchers must check their data very carefully against the above assumption by examining the residuals from the fitted equation. If the above assumption does not hold, an alternative model may be of the form: 


$$
\mathrm{Y}=\beta_{0} \mathrm{X}_{1}{ }_{1} \mathrm{X}_{2}{ }^{\beta_{2}} \mathrm{X}_{3}{ }^{\beta_{3}}+\varepsilon
$$

The general linear regression procedures do not apply to model (5) since it is intrinsically nonlinear. Application of the least squares method to the above model requires iterative procedures for parameter estimation (Draper and Smith 1966, Chapter 10).

\section{Biomass Prediction Equations}

As stated earlier, individual tree or stand biomass may be expressed as a simple power function of individual tree diameter or average stand diameter as:

$$
y=b_{0} x^{b_{1}}+\varepsilon
$$

where: $\mathrm{y}=$ individual tree or stand biomass (either fresh or oven-dry weight), in $\mathrm{kg}$,

$\mathrm{x}=$ tree $\mathrm{dbh}$ or average stand $\mathrm{dbh}$, in $\mathrm{cm}$,

$b_{0}, b_{1}=$ parameters of the model to be estimated.

The simple logarithmic regression model most commonly used for biomass equations assumes a multiplicative error term in the original data of the above power function, i.e., the simplest form of model (3) as:

$$
y=b_{0} x^{b_{1} e}
$$

Taking natural logarithms of both sides of the above model results in:

$$
1 n y=1 n b_{0}+b_{1} 1 n x+1 n e
$$

or

$$
z=b_{6}+b_{1} 1 n x+e ́
$$

where: $z=1 \mathrm{n} y, b_{6}=1 n b_{0}$ and é $=1 \mathrm{n} e$

A number of researchers have employed both the logarithmic model (9) and multiple linear regression models containing several variables such as $\mathrm{dbh}$, height, age, density, etc., as in the following model:

$$
Y=b_{0}+b_{1} x_{1}+b_{2} x_{2}+b_{3} x_{3}+b_{4} x_{4}+e
$$

They have usually compared the resulting regression equations on the basis of their respective $R^{2}$ values, and have concluded that the logarithmic transformation produces a better fit, i.e., a higher $\mathrm{R}^{2}$ than the multiple linear regression model.

It should be noted that the logarithmic model, i.e., model (9), not only assumes a multiplicative error term in the original power function, i.e., model (7), but its resulting $\mathrm{R}^{2}$ and standard error, calculated in the standard way, are in logarithmic scale and therefore are not directly comparable with those obtained from the untransformed models, e.g., model (10).

The value of $R^{2}$ by itself is not a satisfactory measure of goodness of fit, particularly in the case of transformed or constrained models, e.g., logarithmic transformation or when $b_{0}$ is set to zero. Several indices have been devised to serve as a better measure of goodness of fit than $\mathrm{R}^{2}$ for transformed and constrained regression models (Ezekiel and Fox 1959, Furnival 1961, Schreuder and Swank 1971). In the case of constrained models a nonrigorous but intuitively more appealing measure " $\mathrm{S}$ " given below, has been recommended by Ezekiel and Fox (1959) and used by Albini and Brown (1978) and others:

$$
S=1-\Sigma(y-\hat{y})^{2} / \Sigma(y-\bar{y})^{2}
$$

This measure compares the variance about the regression curve to the variance about the mean as does " $R{ }^{2}$ " for an unconstrained model. However, its value is not limited numerically to the range of 0 to 1 . It is restricted to be less than unity, but it can be negative. Following is a comparison of the three models commonly used in biomass studies based on S or generalized coefficient of determination:

A) For the logarithmic model, i.e., model (9), $S$ is calculated as:

$$
S_{z}=1-\Sigma(z-\hat{z})^{2} / \Sigma(z-\bar{z})^{2}
$$

where: $\bar{z}=\Sigma z / n$,

$$
\hat{z}=\hat{b}_{6}+\hat{b}_{1} \ln x
$$

and $\hat{b}_{0}$ and $\hat{b}_{1}$ are the estimates of the parameters which in fact minimize $\Sigma(z-\hat{z})^{2}$.

B) For the multiple linear regression model, i.e., model (10), $S$ is identical to $R^{2}$ and is calculated in the standard way as:

$$
\begin{aligned}
S_{l} & =1-\Sigma(y-\hat{y})^{2} / \Sigma(y-\bar{y})^{2} \\
\text { where: } \bar{y} & =\Sigma y / n, \\
\hat{y} & =\hat{b}_{0}+\hat{b}_{1} x_{1}+\hat{b}_{2} x_{2}+\hat{b}_{3} x_{3}+\hat{b}_{4} x_{4}
\end{aligned}
$$

C) For the simple power function with additive error term, or the simplest nonlinear model, i.e., model (7), $S$ is calculated in a manner similar to the linear model above as:

$$
\mathrm{S}_{n}=1-\Sigma(\mathrm{y}-\hat{\mathrm{y}})^{2} / \Sigma(\mathrm{y}-\overline{\mathrm{y}})^{2}
$$

where: $y=\Sigma y / n$, and

$$
\hat{y}=\hat{b}_{0} x^{b_{1}} \text {. }
$$

To make a valid comparison between $S_{2}$ and either of $S_{1}$ and $S_{n}, S_{z}$ must be adjusted by transforming $z$ to the original scale as:

$$
\mathrm{S}_{\alpha}=1-\Sigma\left(\mathrm{y}-\alpha^{2}\right)^{2} / \Sigma(\mathrm{y}-\overline{\mathrm{y}})^{2}
$$

where: $\alpha$ is the base of logarithmic transformation used and $\mathrm{S}_{\alpha}$ is the $\mathrm{S}$ value adjusted to the original scale and in general is not the same as $\mathrm{S}_{\mathrm{z}}$.

In comparing the two simple power functions, i.e., models (6) and (7), it should be noted that in addition to differences in assumptions regarding the error term and difficulties in comparing their relative goodness of fit, values of estimated parameters will also generally differ. That is, $\hat{b}_{0}, \hat{b}_{1}$ derived to minimize $\Sigma\left(z-\hat{b}_{0}-\hat{b}_{1} 1 n x\right)^{2}$ will not be the same as $\hat{b}_{0}, \hat{b}_{1}$ derived to minimize $\Sigma\left(y-\hat{b}_{0} x^{b_{1}}\right)^{2}$. Therefore, employing model (6) through a nonlinear least squares procedure will usually result in a better fit than the logarithmic transformation, i.e., $S_{n} \geq S_{a^{\prime}}$ In other cases multiple linear models might produce a better fit than logarithmic models, i.e., $\mathrm{S}_{1}>\mathrm{S}_{\alpha}$. In the case of biomass prediction equations, the nonlinear model usually produces a better fit than both the logarithmic and multiple linear regression models.

In addition, the nonlinear model results in nearly bias-free estimates as compared with the logarithmic biased estimates. The following analysis and results should give a clear indication of the superiority of the simple nonlinear model over the logarithmic transformation for biomass equations. 


\begin{tabular}{|c|c|c|c|c|c|}
\hline Variable & Species & Range & Mean & $\begin{array}{l}\text { Standard } \\
\text { deviation }\end{array}$ & $\begin{array}{c}\text { Coefficient } \\
\text { of variation }(\%)\end{array}$ \\
\hline $\mathrm{Dbh}(\mathrm{cm})$ & yellow birch & $1.60-72.00$ & 26.38 & 20.50 & 77.8 \\
\hline \multirow[t]{2}{*}{ Height (m) } & yellow birch & $2.80-26.00$ & 16.66 & 6.41 & 38.5 \\
\hline & sugar maple & $5.40-26.50$ & 19.35 & 5.75 & 29.7 \\
\hline \multirow[t]{2}{*}{ Total tree ovendry weight $(\mathrm{kg})$} & yellow birch & $0.38-3427$ & 638.88 & 943.00 & 137.9 \\
\hline & sugar maple & $1.55-2218$ & 706.92 & 715.00 & 101.1 \\
\hline
\end{tabular}

Table 2. Comparison of various model forms for both local and regional biomass prediction equations based on ' $S$ ' (measure of goodness of fit), SEE, \% bias and relative precision for a sample of 25 yellow birch trees.

\begin{tabular}{llllll}
\hline \multicolumn{1}{c}{ Regression model } & \multicolumn{1}{c}{ Biomass equation } & S & SEE & \% bias & Relative precision \\
\hline$y+b_{0}+b_{1} x^{b 2}+e$ & $\hat{y}=-9.8736+.38387 x^{2.128769}$ & 0.987 & 113.35 & 0.00 & 1.04 \\
$y=b_{1} x^{b 2}+e$ & $\hat{y}=.3533 x^{2.14777}$ & 0.987 & 111.03 & 0.52 & 1.00 \\
$1 n y=1 n b_{0}+b_{1} 1 n x+1 n e$ & $1 n \hat{y}+-1.8906+2.37811 n x$ & $0.995^{\star}$ & $0.186^{\star}$ & & \\
& & $0.967^{\star *}$ & $174.15^{\star *} 5.32$ & 2.46 \\
$y=b_{0}+b_{1} x_{1}{ }^{2}+b_{2} x_{2}+b_{3} x_{1}{ }^{2} x_{2}+e$ & $\hat{y}=4.87+0.465 x_{1}{ }^{2}-1.8119 x_{2}+0.0079 x_{1}{ }^{2} x_{2}$ & 0.987 & 115.12 & 0.07 & 1.07 \\
$y=b_{1} x_{1}^{b} x_{2}^{b}+e$ & $y=0.23088 x_{1}{ }^{2.0701} x_{2}{ }^{0.2323}$ & 0.987 & 112.39 & 0.14 & 1.02 \\
\hline
\end{tabular}

- Both $\mathrm{S}_{z}$ and SEE in logarithmic scale.

* Both $\mathrm{S}_{\alpha}$ and SEE adjusted to original scale.

$\mathrm{x}_{1}=$ tree diameter in $\mathrm{cm}$.

$x_{2}=$ tree height in $\mathrm{m}$.

Table 3. Comparison of various model forms for both local and regional biomass prediction equations based on ' $\mathrm{S}$ ' (measure of goodness of fit), SEE, \% bias and relative precision for a sample of 19 sugar maple trees.

\begin{tabular}{|c|c|c|c|c|c|}
\hline Regression model & Biomass equation & $\mathbf{S}$ & SEE & $\%$ bias & Relative precision \\
\hline$y=b_{0}+b_{1} x^{b_{2}}+e$ & $\hat{y}=-59.28408+1.50403 x^{1.809735}$ & 0.965 & 141.79 & 0.00 & 1.01 \\
\hline$y=b_{1} x^{b_{2}}+e$ & $\hat{y}=.8758 x^{1.93967}$ & 0.968 & 140.13 & 0.60 & 1.00 \\
\hline \multirow[t]{2}{*}{ 1n $y=1 n b_{0}+b_{1} 1 n x+1 n e$} & $\ln \hat{y}=-1.6254+2.34711 n x$ & $0.995^{\star}$ & $0.146^{\star}$ & & \\
\hline & & $0.936^{\star \star}$ & $187.48^{\star \star *}$ & 3.95 & 1.79 \\
\hline$y=b_{0}+b_{1} x_{1}^{2}+b_{2} x_{2}+b_{3} x_{1}^{2} x_{2}+e$ & $\hat{y}=-81.904-.1189 x_{1}^{2}+8.2245 x_{2}+.0313 x_{1}{ }^{2} x_{2}$ & 0.975 & 124.14 & 0.07 & 0.77 \\
\hline$y=b_{1} x_{1}^{b_{2}^{2}} \times \frac{b_{2}^{3}}{2}+e$ & $\hat{y}=.0305 x_{1}{ }^{1.6764} x_{2}^{1.3718}$ & 0.978 & 112.60 & 0.05 & 0.65 \\
\hline
\end{tabular}

* Both $\mathrm{S}_{z}$ and SEE in logarithmic scale.

$\because$ Both $\mathrm{S}_{a}$ and See adjusted to original scale.

$\mathrm{x}_{1}=$ tree diameter in $\mathrm{cm}$.

$x_{2}=$ tree height in $\mathrm{m}$.

\section{Analysis and Results}

Two samples of biomass data consisting of total tree oven-dry weight $(\mathrm{kg})$, Dbh $(\mathrm{cm})$, and height $(\mathrm{H}, \mathrm{m})$ were used. The data were drawn from the Tolerant Hardwood Biomass Inventory, part of the ENFOR project, conducted in Algoma District during the summer of 1978 . Details on data collection and preliminary analysis are given elsewhere. ${ }^{2}$. The first sample consisted of biomass data on 25 yellow birch (Betula alleghaniensis Britton), while the second sample consisted of 19 sugar maple (Acer saccharum Marsh.) trees. Summary statistics for the two sample sets are given in Table 1.

The oven-dry weight and dbh data for both samples were first fitted to the logarithmic model and two simple power functions, one with an intercept (unconstrained) and one without (constrained), in order to compare the relative

2Thomas, J. B. 1978. Report on Project P.21, Tolerant Hardwood Biomass Inventory. Dept. Environ., Can. For. Serv., Sault Ste. Marie, Ont. File Report $60+$ pages. suitability of the three models as applied to local biomass prediction equations. The data sets were also fitted to a multiple linear regression containing $\mathrm{dbh}^{2}, \mathrm{H}$ and $\mathrm{H} \times \mathrm{dbh}^{2}$ as proposed by Evert and Alemdag (1979) and to a power function containing $\mathrm{dbh}$ and $\mathrm{H}$ as independent variables as applied to regional biomass prediction equations. The relative suitability of the above models was judged on their goodness of fit (as measured by S), relative bias, precision and economic applicability. Percent bias is calculated as the, average of differences between observed and predic ${ }^{+}$ied values divided by the observed, times 100 . Relative 'precision is defined as the ratio of mean residual erre, model over another (usualily the one chosen ${ }^{2}$ s the best model). When the valije of this ratio is close to, unity, the two models are consifuered equally precise. If $\mathrm{t}^{\mathrm{t}}$, $1 \mathrm{e}$ relative precision is larger, than one, the first model ', less precise than the secoind (the one chosen, as the be,st), and when the ratio is less than one, the first rnodel is $r$ nore precise than the one chosen. Results of the, above analyses are summarized in Tables 2 and 3. 


\section{Discussion}

Tables 2 and 3 indicate that either of the simple power functions (nonlinear models) resulted in a better fit than the logarithmic model based on adjusted $\mathrm{S}_{\alpha}$. Unfortunately. many researchers in the past have mistakenly chosen the logarithmic model over others solely on the basis of its seemingly higher $S_{z}$ on the logarithmic scale rather than on the basis of adjusted $\mathrm{S}_{\alpha}$. Tables 2 and 3 should clearly indicate the biased estimates resulting from logarithmic models as compared with others. Average percent bias for the logarithmic model was 3.92 and 5.32 for the two data sets while it was nil to $.6 \%$ for all other models.

As expected, models 1 and 2 produced equally good fit in both cases. Although model 2 produced a somewhat biased estimate, owing mainly to its constraint, it was slightly more precise (smaller SEE) than model 1 in both cases. In addition, because of negative intercepts of model 1 in both cases (which will result in unrealistic estimates upon extrapolation in the lower scale) model 2 is considered the best model and therefore all other models are compared with it for relative precision.

Tables 2 and 3 also clearly indicate that the nonlinear model (power function of $\mathrm{dbh}$ and height) proposed here for regional biomass prediction fits both data sets as well as or better than the multiple prediction fits both data sets as well as or better than the multiple linear model proposed by Evert and Alemdag (1979). In general, inclusion of additional variables in a model should improve its goodness of fit; however, when a single variable such as dbh accounts for $96+\%$ of the variation as in the case of biomass equations, addition of height as a second variable does not improve the goodness of fit significantly.

Table 2 clearly indicates that in the case of the yellow birch data, addition of height as a second variable did not improve the goodness of fit at all. In the case of the sugar maple data set (Table 3 ), addition of height as a second variable improved the goodness of fit only by $1-2 \%$, but not significantly. These results are in agreement with those of recent studies by Crow (1978) and Green and Grigal (1978) which indicate that biomass is primarily a function of $\mathrm{dbh}$ and is insensitive to tree height across broad regions. Therefore, one may extend the use of existing biomass equations over broader geographical regions than those for which they were developed. Efforts should be concentrated on broadening the data base of the existing equations rather than trying to develop a whole new set of regional equations containing height and other variables.

\section{References}

Albini, F. A. and Brown, J. K. 1978. Predicting slash depth for fire modeling. USDA For. Serv., Intermountain For. and Range Exp. Stn., Ogden, Utah. Res. Pap. INT-206. 22 p.

Baskervilie, G. L. 1972. use of logarithmic regression in estimation of plant biomass. Can. J. For. Res. 2(1):49-53.

Crow, T. R. 1978. Common regressions to estimate tree biomass in tropical stands. For. Sci. 24(1): 110-114

Draper, N. R. and Smith, H. 1966. Applied regression analysis. John Wiley and Sons Inc. 405 p.

Evert, F. and Alemdag, I. S. 1979. Review of "Equations predicting primary productivity (biomass) of trees, shrubs and lesser vegetation based on current literature", by W. Stanek and D. State, Victoria, BC Inf. Rep. BC-X-183. 58 p. For. Chron. 55(5):209-210.

Ezekiel, M. J. B. and Fox, K. A. 1959. Methods of correlation and regression analysis: Linear and curvilinear. John Wiley and Sons Inc. 308 p.

Furnival, G. M. 1961. An index for comparing equations in constructing volume tables. For. Sci. 7(4):337-343.

Green, D. C. and Grigal, D. F. 1978. Generalized biomass estimation equations for jack pine (Pinus baksiana Lamb.). Coll. For., Univ. Minn., Minn. For. Res. Notes, No. 268. 4 p.

Husch, B., Miller, C. I. and Beers, T. W. 1972. Forest mensuration, 2nd ed. Ronald Press Co., New York. $410 \mathrm{p}$.

Kozak, A. 1970. Methods for ensuring additivity of biomass components by regression analysis. For. Chron. 46:402-404.

Munro, D. D. 1974. Use of logarithmic regression in the estimation of plant biomass: Discussion. Can. J. For. Res. $4(2): 149$.

Newnham, M. 1967. A modification to the combinedvariable formula for computing tree volume. J. For. 65:719-720.

Schreuder, H. T. and Swank, W. T. 1971. A comparison of several statistical models in forest biomass and surface area estimation. p. 125-138 in H. E. Young, Ed. Forest Biomass Studies, IUFRO, Section 25: Yield and Growth. Life Sci. and Agric. Exp. Stn., Univ. Maine, Orono.

Stanek, W. and State, D. 1978. Equations predicting primary productivity (biomass) of trees, shrubs and lesser vegetation based on current literature. Dep. Environ., Can. For. Serv., Victoria, BC Inf. Rep. BC-X-183. 58 p.

\section{kbm FORESTRY CONSUITANTS INC.}

\author{
360 MOONEY STREET \\ THUNDER BAY, ONTARIO \\ P7B 5R4 \\ TEL.: 344-0811
}

\author{
RESOURCE INVENTORY - \\ FOREST MANAGEMENT PLANNING \\ SILVICULTURAL SPECIALISTS \\ SYSTEM DESIGN AND CONTRACT
}

\section{Woodlot Service (1978) Ltd.}

"All Matters Pertaining to Forestry"

GORDON B. YOUNG, B.Sc.F., M.F.

Registered Professional Forester

320 Maple Street

Bus.: 506 - 472-3396

Fredericton, N.B.
Home: 506 - $472-7721$ 